Original Research

\title{
Exploring the Influencing Factors on Breast Self-Examination Among Myanmar Women: A Qualitative Study
}

\author{
Nyein Moh Moh Myint1,2, Nursalam Nursalam¹, and Eka Mishbahatul Mar'ah Has ${ }^{1}$ \\ 1 Faculty of Nursing, Universitas Airlangga, Surabaya, Indonesia \\ 2 University of Nursing, Mandalay, Myanmar
}

\begin{abstract}
Introduction: Breast self-examination (BSE) is the most sensitive and costeffective method to diagnose breast cancer at an early stage in healthcare resources' limited setting. However, the practice of BSE is low in Myanmar. Although various international studies were conducted to clarify the influencing factors in irregular BSE practice, there is a range of different factors and the answer is not yet clear. Hence, this study is aimed to explore the influencing factors on the practice of breast self-examination among Myanmar women.
\end{abstract}

Methods: A qualitative exploratory-descriptive study was conducted on eight women through in-depth semi-structured interviews between February 2020 and March 2020. The samples were women who lived in the rural area of Myanmar and purposive sampling technique was used. Data were analyzed using Colaizzi's method, which consisted of seven stages.

Results: Four themes emerged as the results of the in-depth interview, namely knowledge of breast cancer, knowledge regarding breast self-examination, barriers to performing regular BSE and ways to improve BSE practice.

Conclusion: This study showed that the women were inadequate in knowledge and practice regarding BSE and breast cancer. Some barriers of BSE practice are rooted in the inadequate skill of BSE and the women's attitude. Greater understanding about breast cancer and improving the confidence of women in BSE will lead to better prognosis. Hence, healthcare authorities and providers should encourage a formal health education program and the results from this study hope to be useful in future rural health education programs of BSE practice.

\section{ARTICLE HISTORY}

Received: May 2, 2020

Accepted: May 27, 2020

\section{KEYWORDS}

breast self-examination; Myanmar; rural women

\section{CONTACT}

Nyein Moh Moh Myint \nyeinmoh.1950@gmail.com $\risingdotseq$ Faculty of Nursing, Universitas Airlangga, Surabaya, Indonesia

Cite this as: Myint, N. M. M., Nursalam, N., \& Has, E.M.M. (2020). Exploring the Influencing Factors on Breast SelfExamination Among Myanmar Women: A Qualitative Study. Jurnal Ners, 15(1). 85-90. doi:http://dx.doi.org/10.20473/jn.v15i1.18863

\section{INTRODUCTION}

Breast self-examination (BSE) is important to detect breast cancer early, especially in healthcare resources' limited setting. It is the most sensitive and cost-effective method to diagnose breast cancer at an early stage (Tiwari and Naik, 2018). Even though the women heard about BSE, the majority of the women were low in BSE practice and did not perform regular BSE (Win et al., 2019) (Abolfotouh, BaniMustafa and Mahfouz, 2015; Ahmed, Zahid and Ladiwala, 2018). Although various studies were conducted to clarify the influencing factors in irregular BSE practice, there is a range of different factors and the answer is not yet clear. In Myanmar, the government introduced the BSE method as a primary healthcare level in the Manual for Package of Essential Non-Communicable Diseases (PEN) (Ministry of Health and Sports, 2017). in addition, the government encourages promoting regular BSE practice by sharing information using pamphlets and through government websites (Ministry of Health and Sports, 2019). If breast cancer (BC) detects late with low screening practice, it results in poor prognosis with a high mortality rate. To enhance BSE practice and support the BSE program, the contributing factors of BSE need to be identified. 
BC is a serious health problem for both developed and developing countries (World Health Organization, 2018). According to the International Agency for Research on Cancer (IARC), over 60,000 new cancer cases occur yearly in Myanmar, with BC being the most common among women and 11 people per 100,000 population die of BC (International Agency for Research on Cancer, 2018). Early detection involves an essential role in breast cancer (BC). Of breast cancer cased detected, $73.5 \%$ were by physical examination method, and there was evidence that BSE can find tumors with $22.1 \mathrm{~mm}$ in diameter (Schwab et al., 2015). Moreover, BSE can help to diagnose over $90 \%$ of all breast cancers in an early stage (Mohamed, Ibrahim and Lamadah, 2016). Also, Hassan, Mahmoud and Miller (2015) proved that BSE could detect breast cancers at early stages $(<3)$ and suggested it be applied as a useful screening test with high availability and low costs at the community level (Hassan, Mahmoud and Miller, 2015).

However, BSE practice is still low in practice. A previous study conducted in Myanmar showed that only $16.7 \%$ of the respondents could talk about BSE, and only $13.3 \%$ of them performed it (Win et al., 2019). The previous international studies identified the various impacting factors that can influence on BSE. As socio-demographic factors, age, marital status, personal history of breast disease (Vasishtaa et al., 2018), level of education (Febriyanti et al., 2018), and work status (Abolfotouh et al., 2015) have a significant relation with BSE practice. According to a cross-sectional study conducted in Bali, it described that those having good level of knowledge of BSE, perceived benefits, perceived low barriers, and high level of self-efficacy were more likely to perform BSE (Febriyanti et al., 2018). Also, the reasons for not performing BSE included that they did not know how to do it, had no symptoms of breast cancer and worried about detecting breast cancer, respectively (Vasishtaa et al., 2018).

To organize an effective program in improving regular BSE practice among women, understanding the impacting factors on BSE practice plays a crucial role. Hence, this study is aimed to explore the influencing factors on the practice of breast selfexamination among rural women in Myanmar.

\section{MATERIALS AND METHODS}

This research is a qualitative research using a descriptive exploratory approach. Eight women who met the criteria were recruited by using purposive sampling. Targeting criteria included women who wanted to share their experience for this research, women who had heard about BSE and women aged between 20 to $45 y$ years. Data collection was carried out at two villages of Meiktilar Township, Myanmar between February 2020 and March 2020.

The data were collected by using individual indepth interview until the data were saturated. Openended semi-structured questions were used and the interview took 30 to 60 minutes at the respondents' home or convenient place. Before conducting the interview, the researcher firstly explained the purpose of the study and procedure. Then, if the women desired to participate, took consent from all women. All interviews were audio-recorded and field notes taken after getting permission from respondents. The main guided items used in the interview were "What do you understand about breast cancer?" "What do you think of breast selfexamination?" "Have you ever examined your breasts?" and "How can BSE practice be improved?" Ethical approval was obtained from the Institutional Review Board, Department of Medical Research, Yangon, Myanmar with the number (Ethics/DMR/2020/004) and the Research Ethics Committee of Faculty of Nursing, Universitas Airlangga with the number (No: 1799-KEPK).

Interview data were transcribed from original recordings and field notes after data collection, and the accuracy checked to reduce mistakes in writing the transcript. Then, data were analyzed using the Colaizzi's method, which consisted of seven steps. Peer check and immersed data to ensure the rigor of the findings were used as well. Four major themes emerged, namely, knowledge of breast cancer, knowledge regarding BSE, barriers to performing regular BSE, and ways to improve BSE practice.

\section{RESULTS}

Eight women from two villages of Meiktilar township, Myanmar, participated in this study. All of the women were Buddhists and aged between 21 to 42 years. Among them, two women had a history of excision of a breast lump, and one woman had a history of cyst in breast. All women had heard about BSE. One of them performed BSE every day, four of them sometimes and three of them never used BSE. Three women obtained information from healthcare providers, three from peers and two from audiovisual media. The characteristics of participants are shown in Table 1, and then four major themes are described in detail with the respondents' responses.

\section{Knowledge of breast cancer}

The results showed that the women did not know about breast cancer well, especially in sign and symptoms, risk factors, screening and management. The majority of the women, except one, agreed that breast cancer was a painful lump. Some of their responses were:

"Breast cancer is a serious and fatal disease. I am scared that I suffer from breast cancer. It is a painful lump and gradually increases in size and pain intensity" (P1). 
Table 1 Characteristics of participants

\begin{tabular}{ccccccccc}
\hline Code.No & Age & $\begin{array}{c}\text { Marital } \\
\text { Status }\end{array}$ & Religion & Education & $\begin{array}{c}\text { Family } \\
\text { history of } \\
\text { BC }\end{array}$ & $\begin{array}{c}\text { History of } \\
\text { Breast } \\
\text { disease }\end{array}$ & $\begin{array}{c}\text { BSE } \\
\text { practice }\end{array}$ & Sources of information \\
\hline P1 & 42 & Married & Buddhism & Graduate & No & Breast lump & Sometimes & Healthcare person \\
\hline P2 & 21 & Single & Buddhism & University & No & No & Never & Peer \\
\hline P3 & 40 & Single & Buddhism & High school & No & Cyst & Sometimes & Healthcare person \\
\hline P4 & 40 & Married & Buddhism & Graduate & No & No & Never & Healthcare person \\
\hline P5 & 25 & Married & Buddhism & Graduate & No & No & Never & Peer \\
\hline P6 & 31 & Single & Buddhism & High school & Yes & No & $\begin{array}{c}\text { Always } \\
\text { (everyday) }\end{array}$ & Audio-visual Media \\
\hline P7 & 36 & Married & Buddhism & Middle school & No & No & Sometimes & Peer \\
\hline P8 & 39 & Married & Buddhism & High school & No & Lipoma & Sometimes & Audio-visual Media \\
\hline
\end{tabular}

*P=Participant

"It is the lump in the breast that can disseminate to other parts of the body. If the lump has no pain, there is no need to worry. There is no problem. It is not breast cancer" (P3).

"....it is a painful ulcer or lump, but I do not know well" (P4).

"I do not know the symptoms...It is a lump and painful" (P5).

Regarding risk factors and causes, many different aspects appeared. They assumed that menopausal or unmarried women can suffer more breast cancer. Some of the women believed they had no chance to experience breast cancer. Some of their opinions were:

"It is common in women after menopause and in spinsters. I believe that I cannot suffer from BC. I am not old age and already married" (P2).

"I never think I can suffer breast cancer because I have no breast disease" (P4).

Although there was no scientific evidence on the relationship between wearing a bra and breast cancer (American Cancer Society, 2017), the women believed there was a relationship. Two of the women believed wearing a nylon bra as a cause of breast cancer while one of them suggested removing the bra at free time. The women explained the following:

"The women who always wear nylon bras suffer from breast cancer. So, I always wear cotton ones" (P3).

"Wearing a tight bra and nylon bra (that can feel hot and sweating) causes breast cancer and other breast diseases" (P7).

"I think it (bra) maybe, but not sure. Should remove at night and free to prevent BC" (P5).

A controversial response was found in gripping or massaging of the breast by hand and breast cancer. The women said:

"I don't know the causes of BC. I think if there is an injury of the breast caused by handgrip of the breast during sexual intercourse. It will become breast cancer later. So, I always remind my husband" (P5).
"I think it is not related to a handgrip on the breast. Even if there is a lump, it will reduce by massaging" (P1).

On screening method, all of them accepted that examination of the breast was a way to detect breast cancer. One woman recommended a regular checkup (every three years) whereas another woman answered there was no need for a regular check-up. All of them accepted that BSE was a way to detect breast cancer.

\section{Knowledge regarding BSE}

The level of understanding of BSE was inadequate among participants. Although the women had already heard of and accepted BSE as a way to detect breast cancer, they did not know the method accurately. Their uncertainty was seen in the following responses:

“....just heard about BSE. Women should perform BSE. But it is not sure how to do it" (P2) (P4).

"I heard about BSE. ................... but not know the way to do" (P7).

"I heard about BSE from the doctor who removed my breast lump. She taught me how to palpate the breast briefly, but now I forget the steps" (P1).

The majority of the samples assumed that BSE was the palpation of the breast by hand to find the lump and there was no need to inspect the breast. One of them described that she felt embarrassment with inspection. Some of them thought that there was no need to palpate the axilla region. Some of their responses were the following:

"BSE is squeezing of the breast thoroughly with hand in sitting position at the time of bathing, but not the axilla because of breast cancer" (P6).

"BSE is the palpation of the breast so see if there is a lump or not. I think there is no need to palpate the axilla region ...." (P8).

"I palpate both the breast and the nipple, but never look at in the mirror. It makes me embarrassed" (P1).

Although regular practice in BSE is important to find abnormal changes in the breast, the women 
who participated in this study did not implement this. Most of them performed BSE when they felt something in the breast and before menstruation. Some of their responses were:

"If there is a pain in the breast, I sometimes perform the BSE, but not regularly. As for me, there is no need to do a regular exam if there is no problem" (P1).

"Sometimes, I perform when I feel something in my breast. I think there is no need to do it regularly" (P8)

"I do BSE sometimes. If I suffer pain in the breast (usually before menstruation), I remember to take BSE" (P3).

On the other hand, one woman performed BSE every day (sometimes, more than once a day). She stated that:

"I always perform BSE every day. Sometimes, I palpate more than once a day. My aunt (father's sister) suffered from breast cancer with a painful feeling and groaning before she died. I'm afraid of dying with breast cancer" (P6).

Moreover, some misunderstandings on the lump of BSE had occurred. One of the women described that "BSE is the palpation of the breast. The women should perform BSE. If there is a painful lump immediately go to healthcare providers. The painless lump has no need to be a worry. It is not a problem." The women assumed that only females need to perform BSE. Therefore, the women needed more information about BSE, including who should perform, how to do it, when to do it, and which region should be performed.

\section{Barriers to perform regular BSE}

Generally, the women had no regular BSE practice. The majority of the participants reported that they did not know how to do BSE correctly. Some women performed BSE sometimes when they felt something or had pain in the breast. The women who had never performed BSE answered that they were busy; they did not have enough time to palpate, no history of a breast lump, no pain in the breast and assumed no need to do BSE. Their responses were as following:

"... I have no history of breast disease. I do not feel pain in my breast. I think that I do not need to do breast examination" (P2).

“... because I do not know how to do it, and I have no extra time to do it" (P4).

"I rarely perform it because I have no problem with breast and usually go to an obstetrician and gynecologist (OG) to get a child. Nevertheless, I have never asked about breast cancer, and also she does not suggest me to perform BSE" (P7).

\section{Ways to improve BSE practice}

Based on the participants' view, health education involves a crucial role. They stated that they are eager to learn how to do BSE systematically, and they think that providing health education with practical sessions from the healthcare provider is effective.
They also suggested that healthcare providers should be female, and group discussion should also be included. Some of the samples described their concern to improve BSE practice as follows:

"If there are health talks about BSE, I would like to join. I think it should include the explanations with the picture, the practical examination one by one. The practical session should be how to understand and classify the findings from other breast diseases" (P3).

"Do I need to perform BSE? If someone explains the requirement of BSE and teaches how to do it, I will perform it" (P5).

"I think that health education with peer group discussion will get the chance to ask for the unclear points. Besides, I always encourage others to palpate the breast if they have an interest" (P6).

"To understand and perform BSE well, I would like to learn the method of BSE from female healthcare providers together with my peers. I can discuss and remember easily. If I forget something, I can ask my friends" (P7).

\section{DISCUSSION}

The present study was conducted with the aim to explore the contributing factors on regular BSE practice. The samples who participated in this study were aged women between 21 to 42 years. This study revealed the perceptions of young women on BSE because breast tumors in young female showed more aggressive and tended to be diagnosed in more advanced stage (Radecka and Litwiniuk, 2016). As a result of the recent study, four major themes emerged, namely, knowledge of breast cancer, knowledge regarding BSE, barriers to performing regular BSE, and ways to improve BSE practice.

The study results showed that women with a history of the breast-related disease and family history of breast cancer had more tendencies to do BSE. This finding was in concordance with previous study (Abolfotouh, BaniMustafa and Mahfouz, 2015). The sample obtained the information mainly from healthcare providers and peers. Similar results were also seen in the study by Hanson, Wyk and Adejumo (2016), which described that healthcare workers were the primary source of health information in reproductive health issues (Hanson, Wyk and Adejumo, 2016). In Myanmar, basic health services in the rural area are provided primarily by the midwives and community health nurse. They should provide health information widely in the community and encourage women to perform BSE regularly.

Although knowledge is the essential requirement to change behaviors, the understandings of breast cancer and BSE among women were low in this study. Khiyali, Aliyan and Kashf (2017) proved that improving the knowledge of $\mathrm{BC}$ and $\mathrm{BSE}$ improved the BSE behaviors which can reduce the mortality rate with breast cancer. 
Another study showed that there was a significant relationship between knowledge and BSE practice (Noor et al., 2018). In this study, some of the women knew about breast cancer and that it is common in women, but they denied that they had the chance to suffer from breast cancer with the reasons of young age and marital status. The women heard about BSE from different sources and accepted that women should palpate the breast to find the breast lump. However, the results showed that the information that they obtained is not enough and it required an organized health education program, including basic knowledge about breast cancer and BSE.

The perceived low barrier is one of the significant factors that can influence on BSE (Febriyanti et al., 2018). In this study, the causes of failures to do BSE practice were that they do not know the method of BSE, no time to perform BSE, busy and inadequate time to palpate, no history of a breast lump, no pain in the breast and assumed no need to do BSE. Similarly, another study showed that the women in Myanmar had a negative attitude toward BSE with embarrassment to do, time-consuming, fear of discovering tumors, and difficulties to do (Myint, 2015). Based on the results, the barriers that occurred among women were rooted in inadequate knowledge regarding BSE, risk factors, and signs and symptoms of breast cancer. So, enhancing knowledge is considered to remove or reduce the perceptions of barriers.

In this study, the majority of the women assumed that health education is essential to improve BSE practice. The women were willing to learn about BSE method with practical sessions until understanding how to interpret the findings. They also suggested using visual aids like diagrams to get precise information. Similarly, a study conducted in Malaysia proved that there was a significant increase in knowledge and performance of BSE. Health intervention of that study was carried out by different teaching methods such as PowerPoint presentation, using educational videos, group discussion, and performing breast examination on models (Masoudiyekta et al., 2017). Similarly, previous studies proved that health education is essential to obtain awareness about BC and encourage performing BSE practice. An educational intervention based on the health belief model (HBM) on BSE behavior showed that it is effective in promoting BSE behaviors (Khiyali, Aliyan and Kashf, 2017). Therefore, theory-based health education combined with different teaching methods should be considered in enhancing BSE practice.

\section{CONCLUSION}

This study showed that the women living in the rural area of Myanmar were low in knowledge and practice regarding BSE and breast cancer. Some barriers that contribute to the BSE practice were rooted in inadequate knowledge and skill of BSE and the women's attitude. By providing health education, the more the women understand about BC and BSE, the earlier they detect breast cancer. Consequently, the prognosis of breast cancer will be better and the mortality rate with breast cancer will reduce. Hence, healthcare authorities and providers should develop a formal health education program on BC and BSE. The results from this recent study hope to be useful in future health education programs in the rural area.

\section{REFERENCES}

Abolfotouh, M. A., BaniMustafa, A. A. and Mahfouz, A. A. (2015). Using the health belief model to predict breast self examination among Saudi women. BMC Public Health, 15(1). doi: 10.1186/s12889-015-2510-y.

Ahmed, A., Zahid, I. and Ladiwala, Z. F. R. (2018). Breast self - examination awareness and practices in young women in developing countries: A survey of female students in Karachi , Pakistan. Journal of Education and Health Promotion, 7, pp. 1-9. doi: 10.4103/jehp.jehp.

American Cancer Society (2017). About Breast Cancer: Breast Cancer Basics. Available at: https://www.cancer.org/content/dam/CRC/P DF/Public/8577.00.pdf (Accessed: 29 October 2018).

Febriyanti, N. M. A., Lubis, D., Wirawan, D.N. and Suariyani, P.. (2018). The determinants of early breast cancer detection via breast selfexamination ( BSE ) in Denpasar, Bali. Public Health and Preventive Medicine Archive (PHPMA), 6(1), pp. 37-41. doi: 10.15562/phpma.v6i1.7.

Hanson, V. F., Wyk, B. Van and Adejumo, O. (2016). Breast self-examination knowledge and practice among women in a rural community in south- west Nigeria: a qualitative approach, MIDIRS Midwifery Digest, 26(4), pp. 525-530.

Hassan, L. M., Mahmoud, N. and Miller, A. B. (2015). Evaluation of effect of self-examination and physical examination on breast cancer. The Breast, 24, pp. 487-490. doi: 10.1016/j.breast.2015.04.011.

International Agency for Research on Cancer (2018). Myanmar Data Fact Sheet. doi: https://gco.iarc.fr/today/fact-sheetspopulations.

Khiyali, Z., Aliyan, F. and Kashf, S. H. (2017). Educational Intervention on Breast SelfExamination Behavior in Women Referred to Health Centers: Application of Health Belief Model. Asian Pacific Journal of Cancer Prevention, 18(10), pp. 2833-2838. doi: 10.22034/APJCP.2017.18.10.2833.

Masoudiyekta, L. Dashtbozorgi, B., Gheibizadeh, M., Malehi, A.S. and Moradi , M.. (2017). Effect of Education Based on Health Belief Model on the Behavior of Breast Cancer Screening in Women. Asia-Pacific Journal of Oncology Nursing, 4(2), pp. 95-7. doi: 
10.4103/apjon.apjon.

Ministry of Health and Sports (2017). Training Of Trainer Manual For Package of Essential NonCommunicable Disease Interventions (PEN), Ministry of Health and Sports, Myanmar. Nay Pyi Taw: Ministry of Health and Sports, Myanmar.

doi: 10.1017/CBO9781107415324.004.

Ministry of Health and Sports (2019). Breast Selfexamination. Nay Pyi Taw: Ministry of Health and Sports, Myanmar.

Mohamed, H. A. E. A., Ibrahim, Y. M. and Lamadah, S. M. (2016). Application of the Health Belief Model for Breast Cancer Screening and Implementation of Breast Self-Examination Educational Program for Female Students of Selected Medical and Non-Medical Faculties at Umm al Qura University. Life Science Journal, 13(5), pp. 21-33. doi: 10.7537/marslsj13051603.Key.

Noor, S., Hardiyanti, D., Nursalam, Yunitasari, E., Tristiana, Rr D. (2018).Analysis of factors relating to practice of breast self-examination (BSE) among women in Indonesia. Indian Journal of Public Health Research and Development, 9(12), pp. 595-599. doi: 10.5958/0976-5506.2018.01902.2.

Radecka, B. and Litwiniuk, M. (2016). Breast cancer in young women. Ginekologia Polska, 87(9), pp. 659-663. doi: 10.5603/GP.2016.0062.
Schwab, F. D., Huang, D.J.,Schmid, S.M., Schötzau, A. and Güth,U. (2015). Self-detection and clinical breast examination: Comparison of the two "classical" physical examination methods for the diagnosis of breast cancer. The Breast, 24(1). doi: 10.1016/j.breast.2014.11.008.

Tiwari, A. and Naik, M. (2018). Effectiveness of structured teaching program on knowledge and practice regarding breast self-examination among college girls in a selected college of Bhilai , Chhattisgarh, India. International Journal of Community Medicine and Public Health, 5(9), pp. 4028-4036.

Win, T., Aung, K.M.S.S., Aung, K.O.S. and Yee, M.M. (2019). A gap between knowledge and practice: Breast cancer knowledge and practice of breast self-examination (BSE) in community. Available at: https://www.researchgate.net/publication/3 30661109_A_gap_between_knowledge_and_pr actice_Breast_cancer_knowledge_and_practice _of_breast_selfexamination_BSE_in_community (Accessed: ).

World Health Organization (2018). WHO | Breast Cancer. Available at: http://www.who.int/cancer/prevention/diag nosis-screening/breast-cancer/en/ (Accessed: 29 October 2018). 